Copies of spectra for:

\title{
Direct and Efficient One-pot Preparation of Ketones from Aldehydes using $\mathbf{N}$-tert- Butylphenylsulfinimidoyl Chloride
}

James J. Crawford, ${ }^{\dagger}$ Kenneth W. Henderson ${ }^{\ddagger}$ and William J. $\mathrm{Kerr}^{\dagger *}$

Department of Pure and Applied Chemistry, WestCHEM, University of Strathclyde, 295 Cathedral Street, Glasgow, Scotland, UK G1 1XL

Department of Chemistry and Biochemistry, University of Notre Dame, 251 Nieuwland Science Hall, Notre Dame, IN 46556-5670, USA

w.kerr@strath.ac.uk 


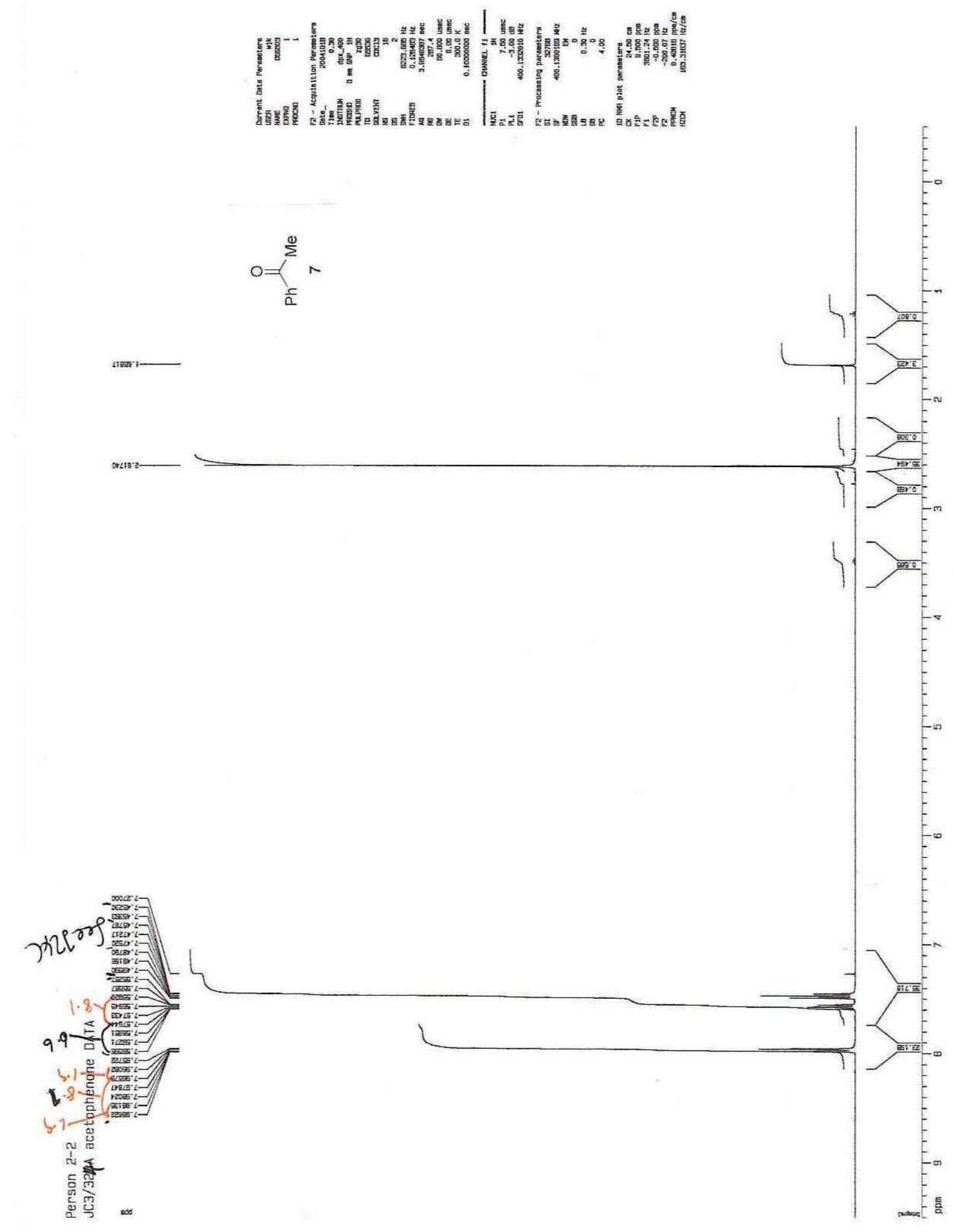




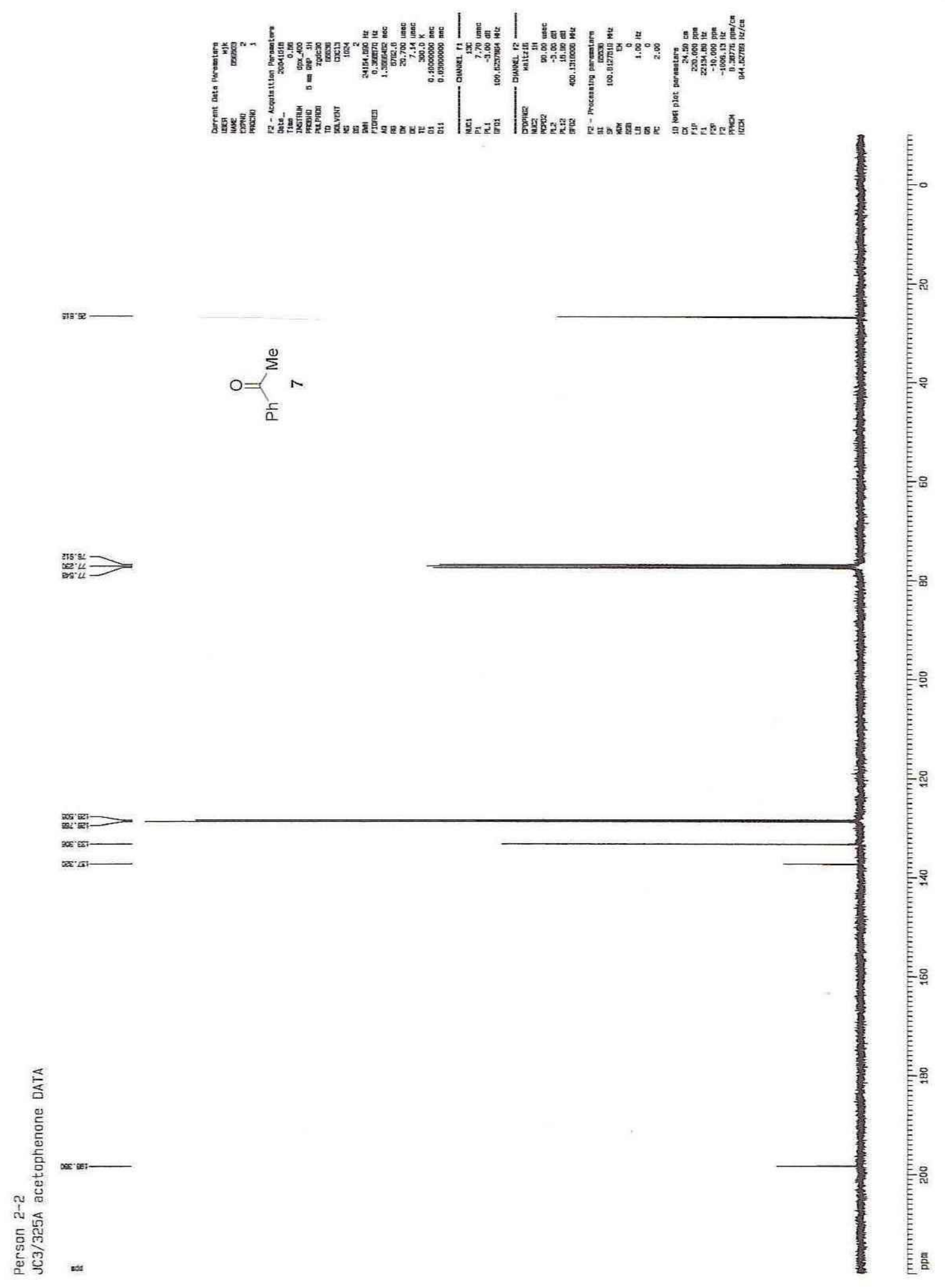




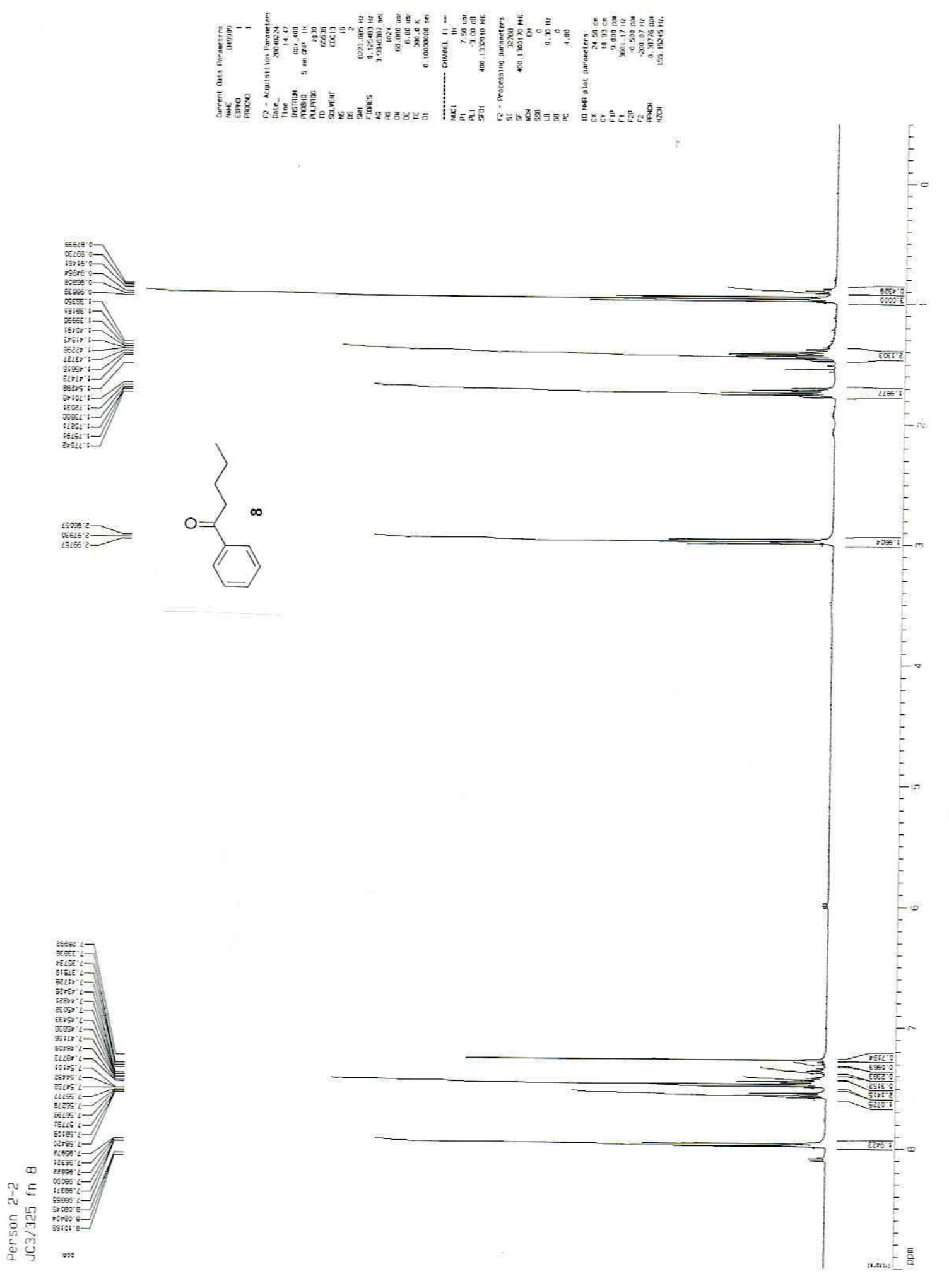




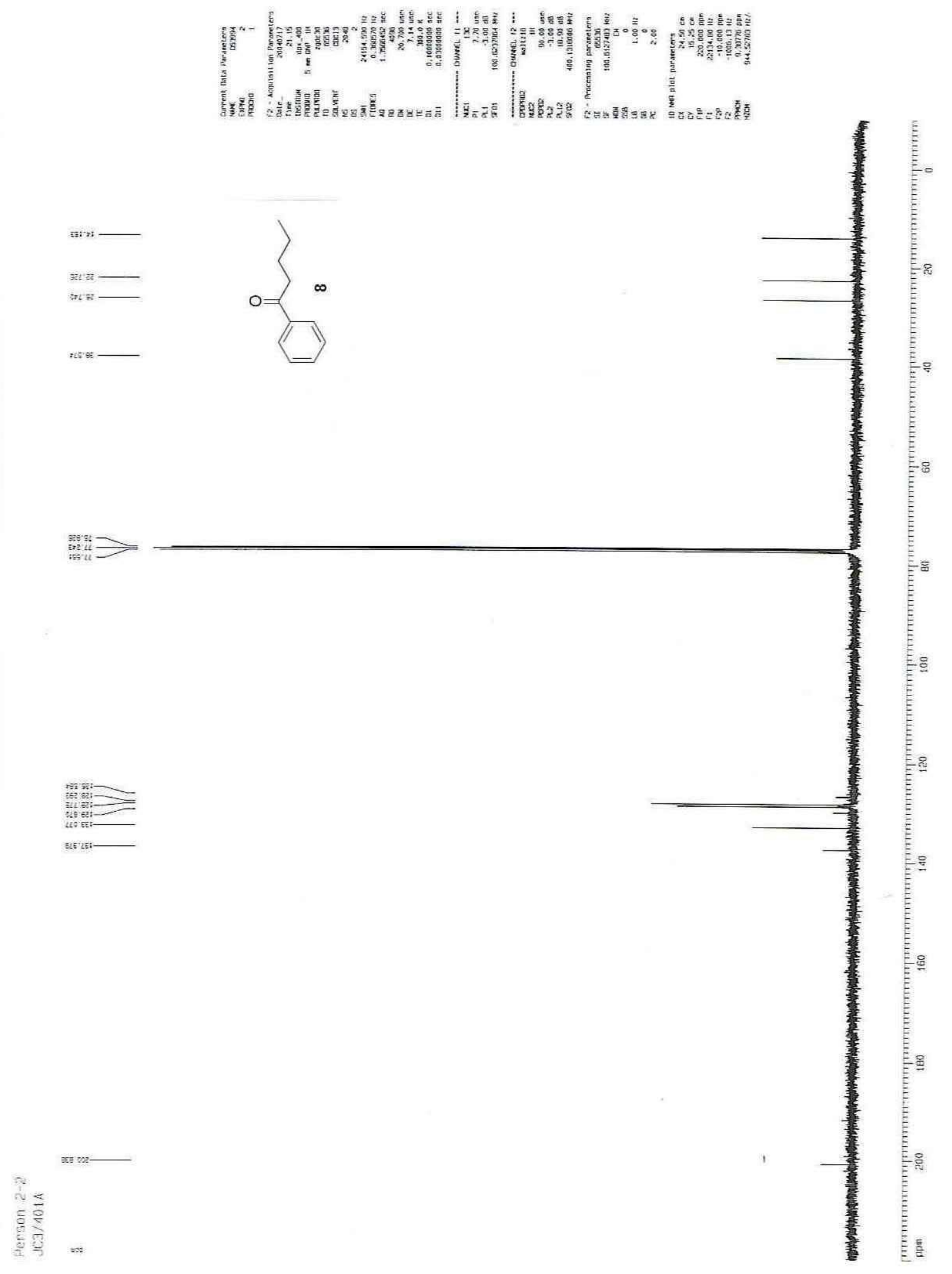




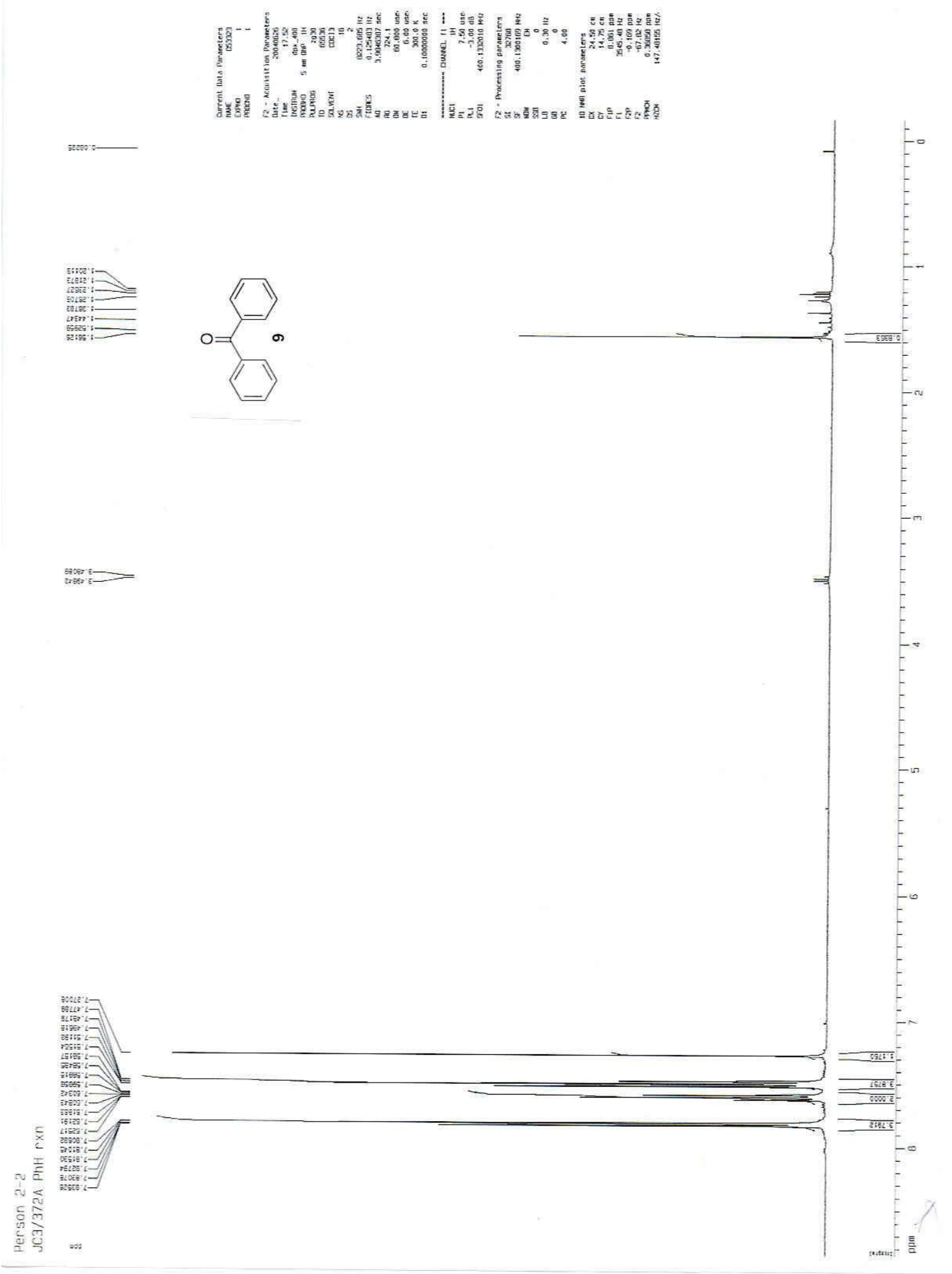



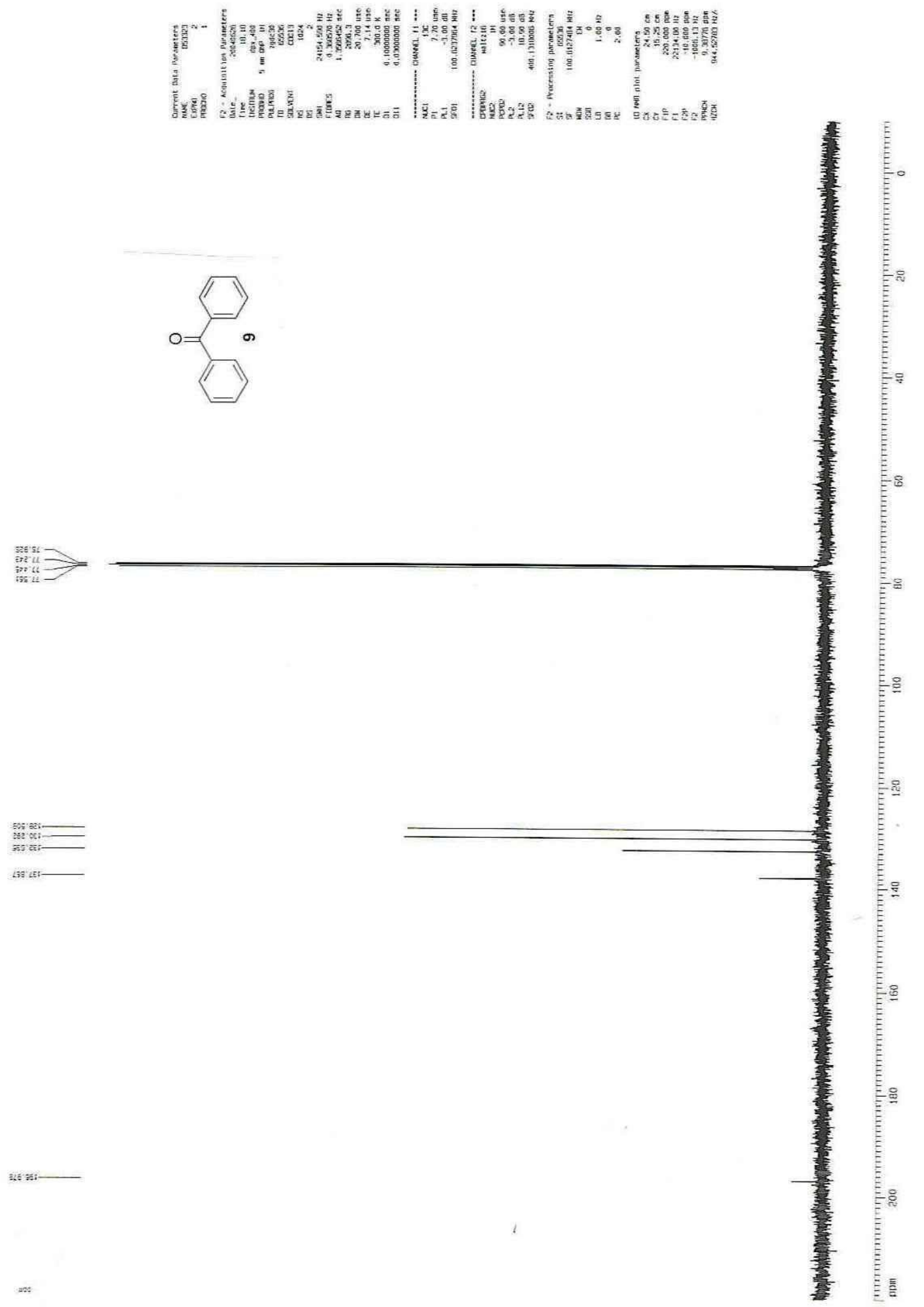


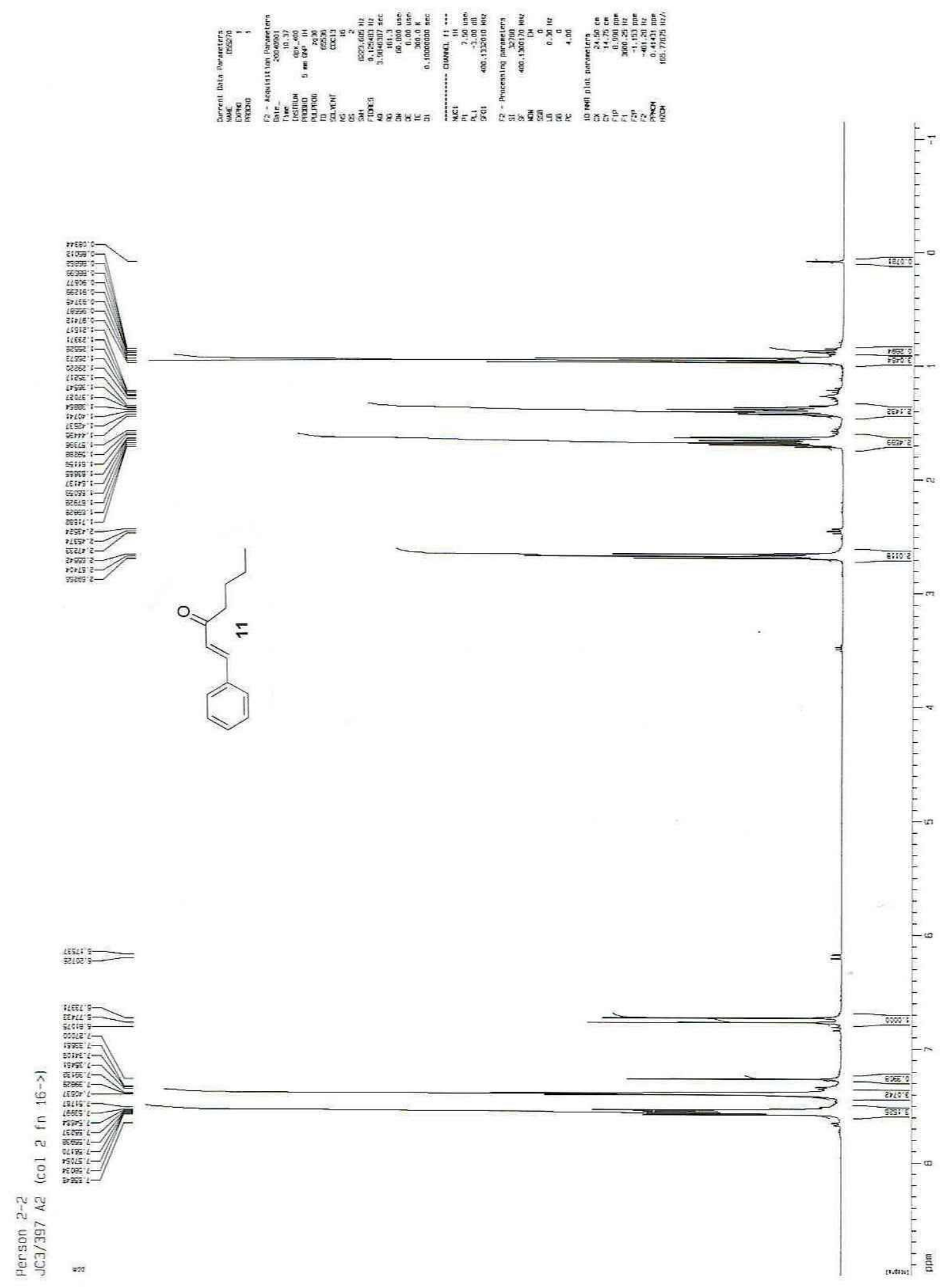




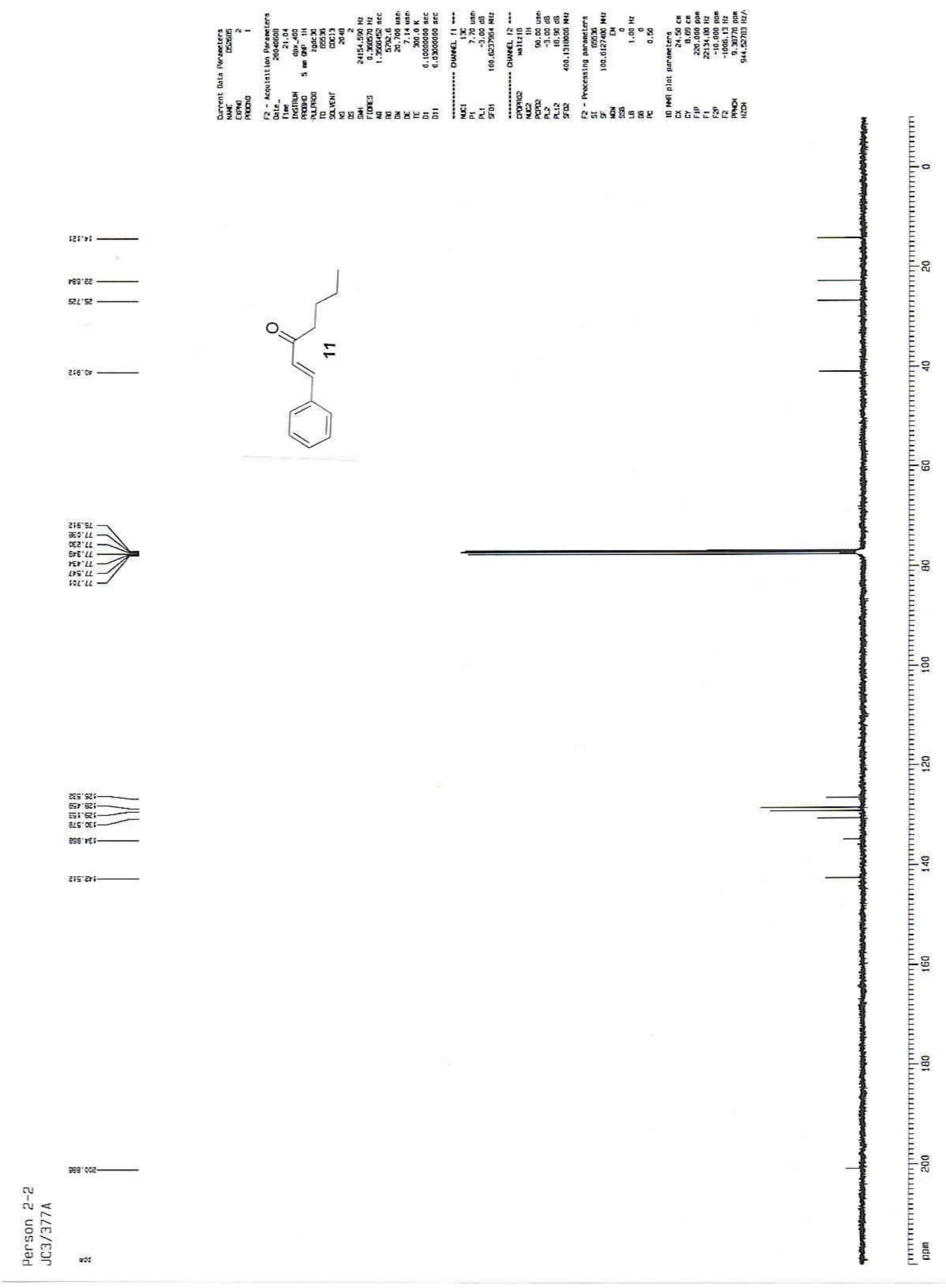




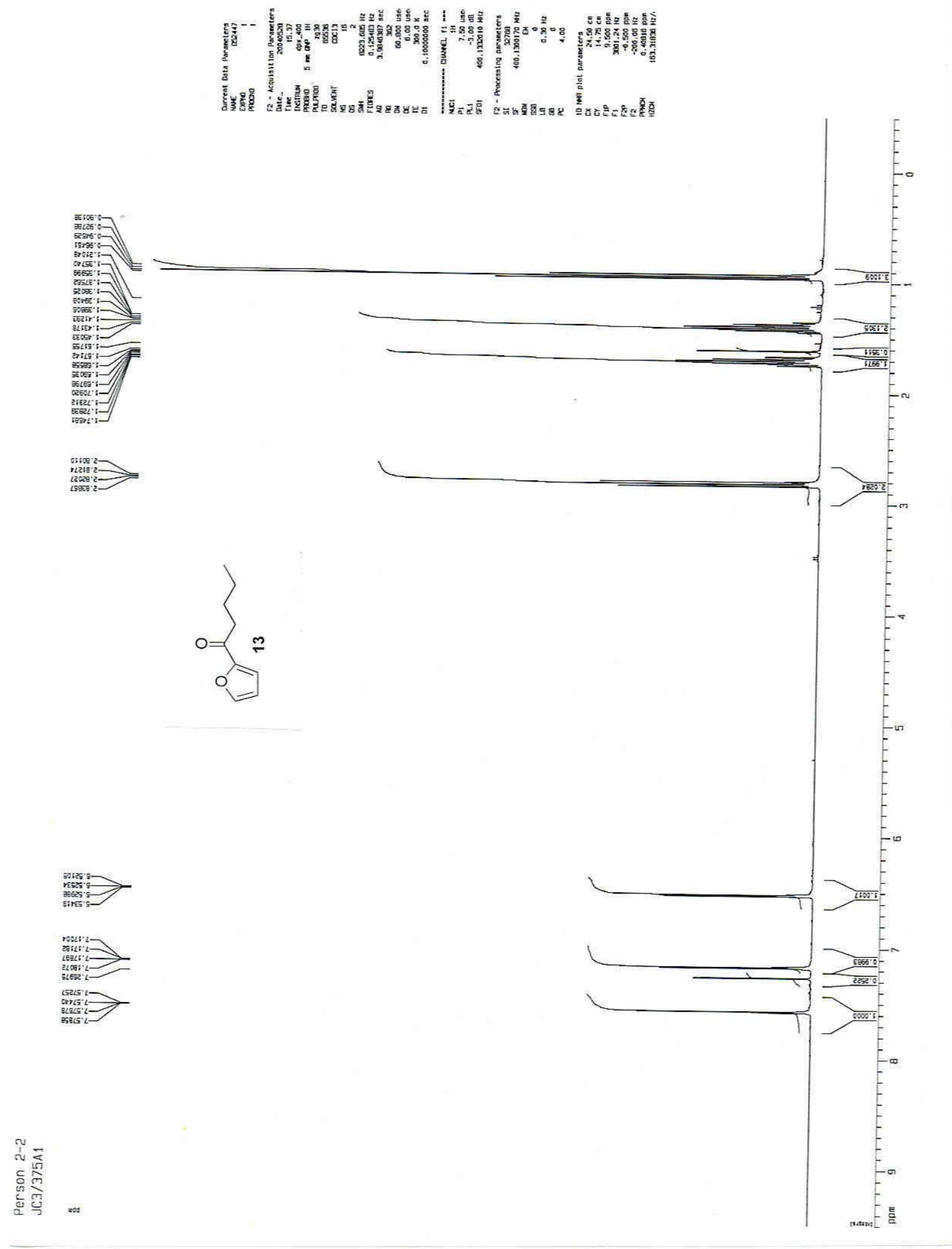




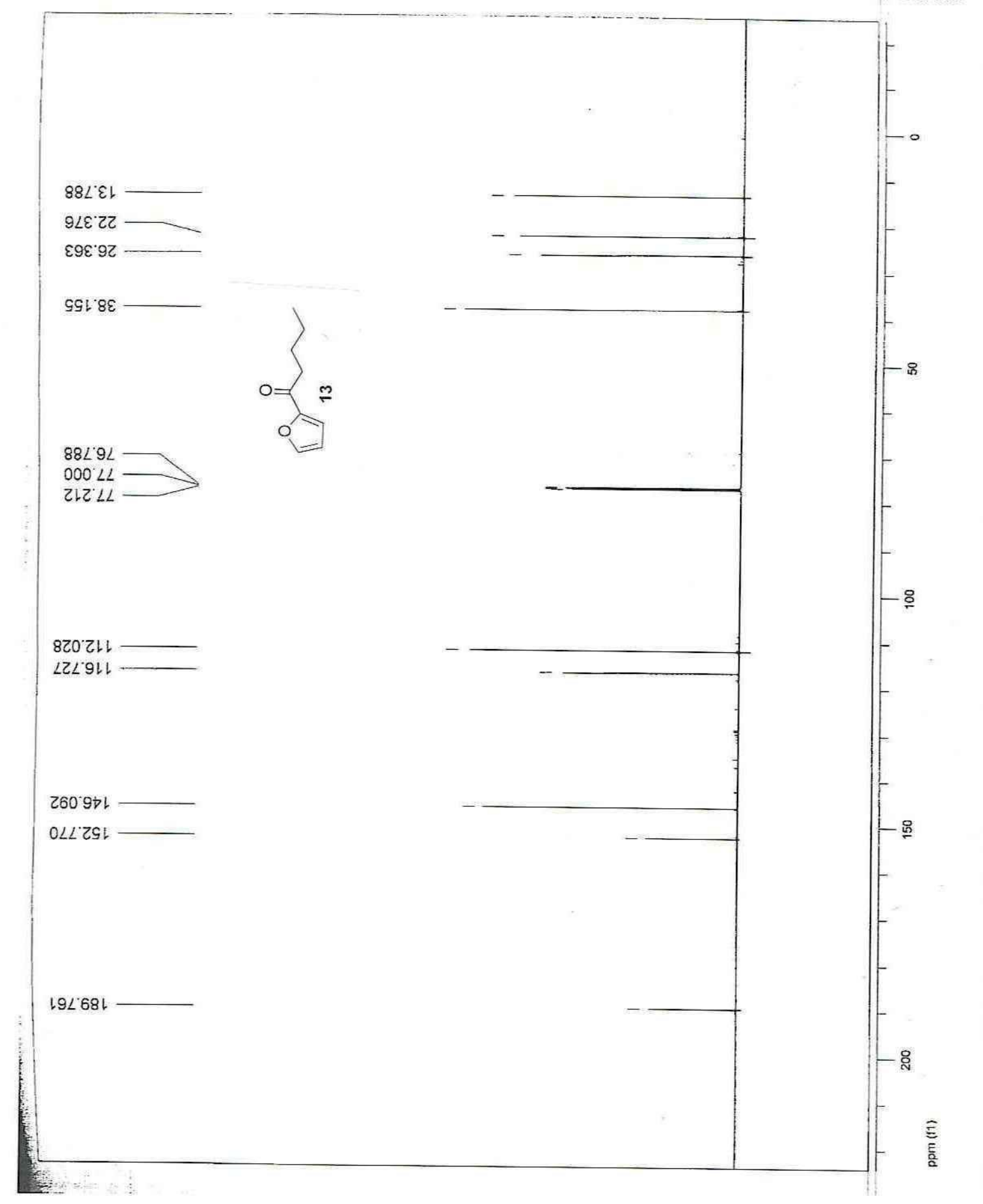




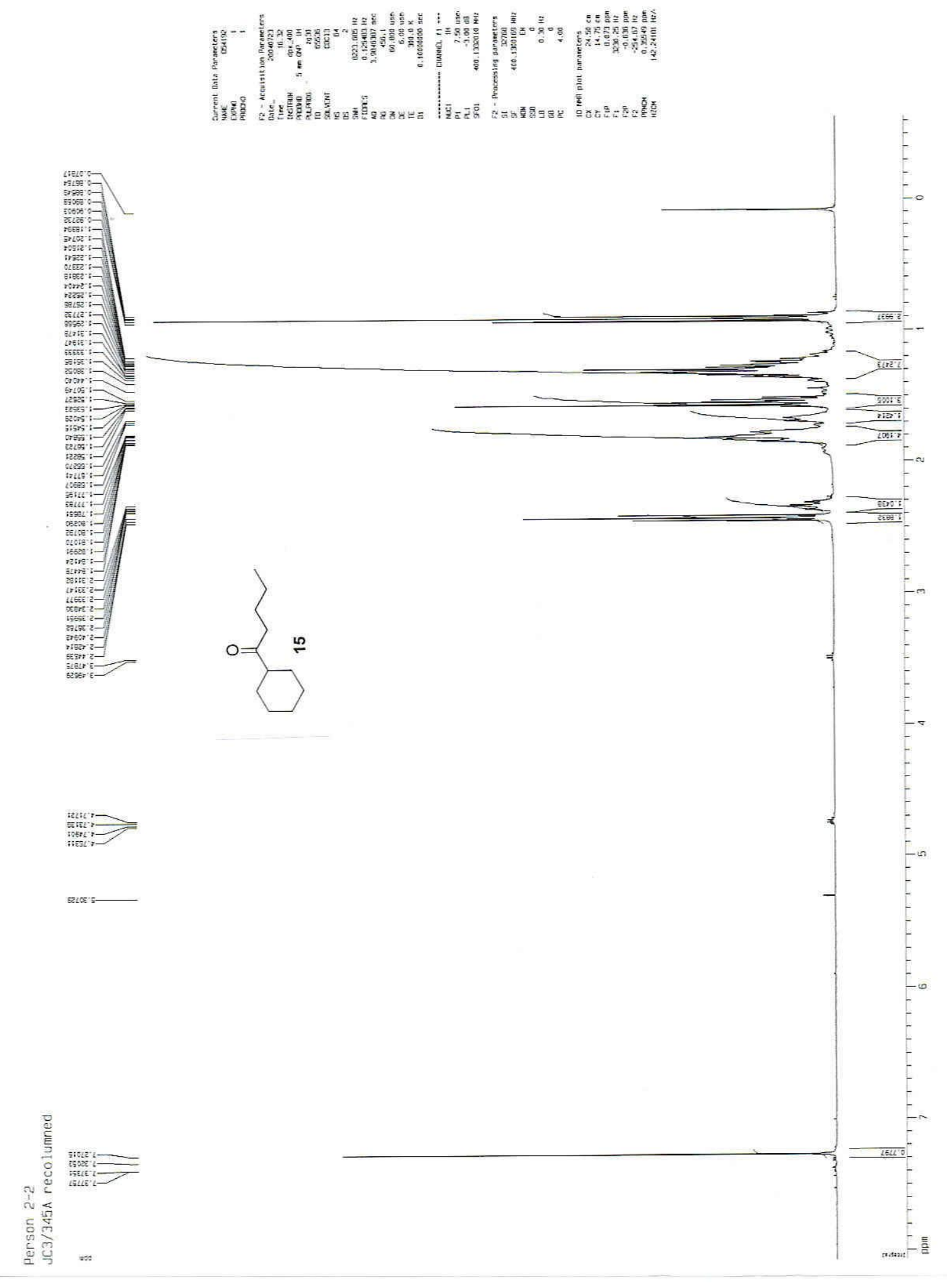




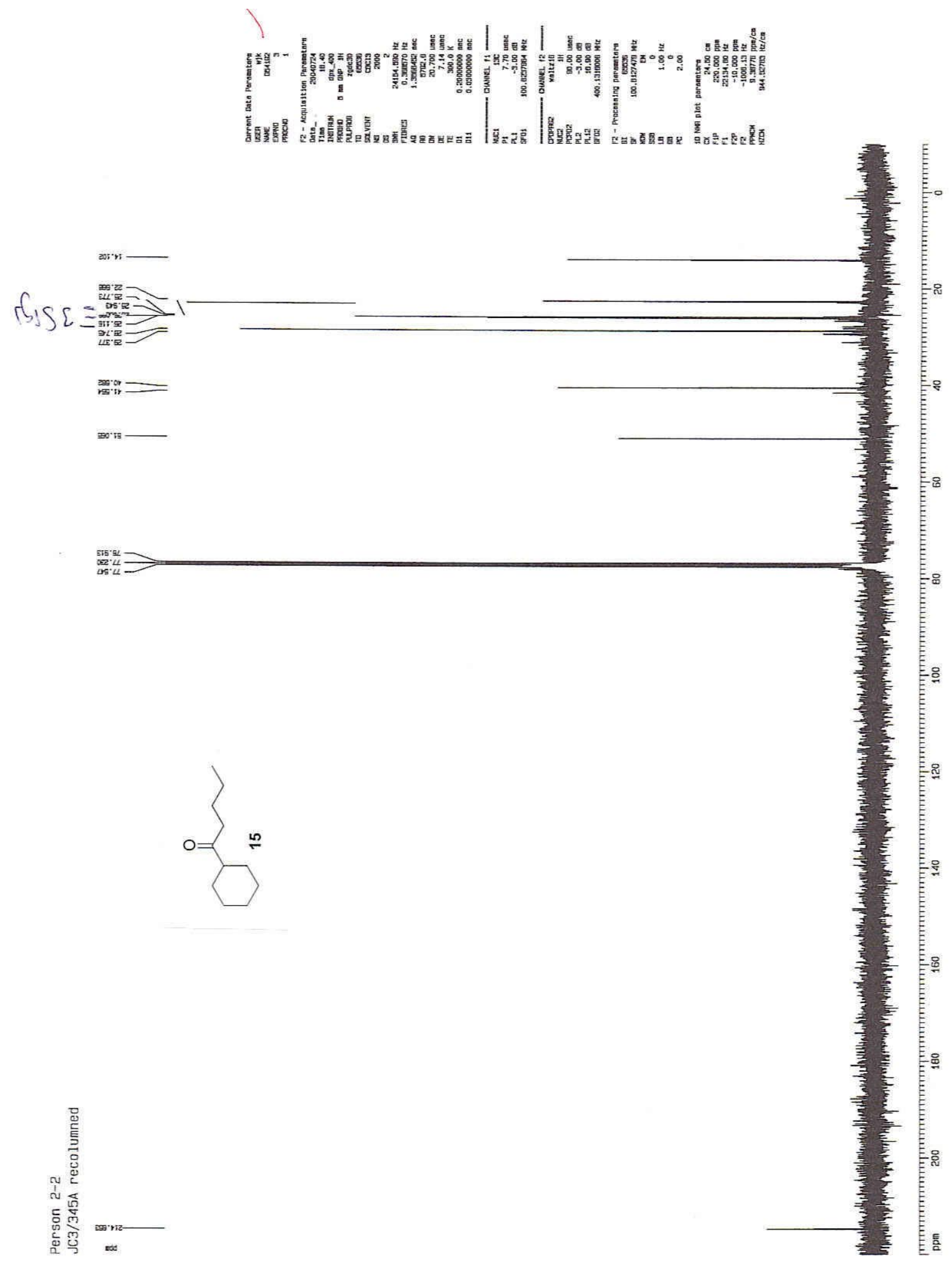




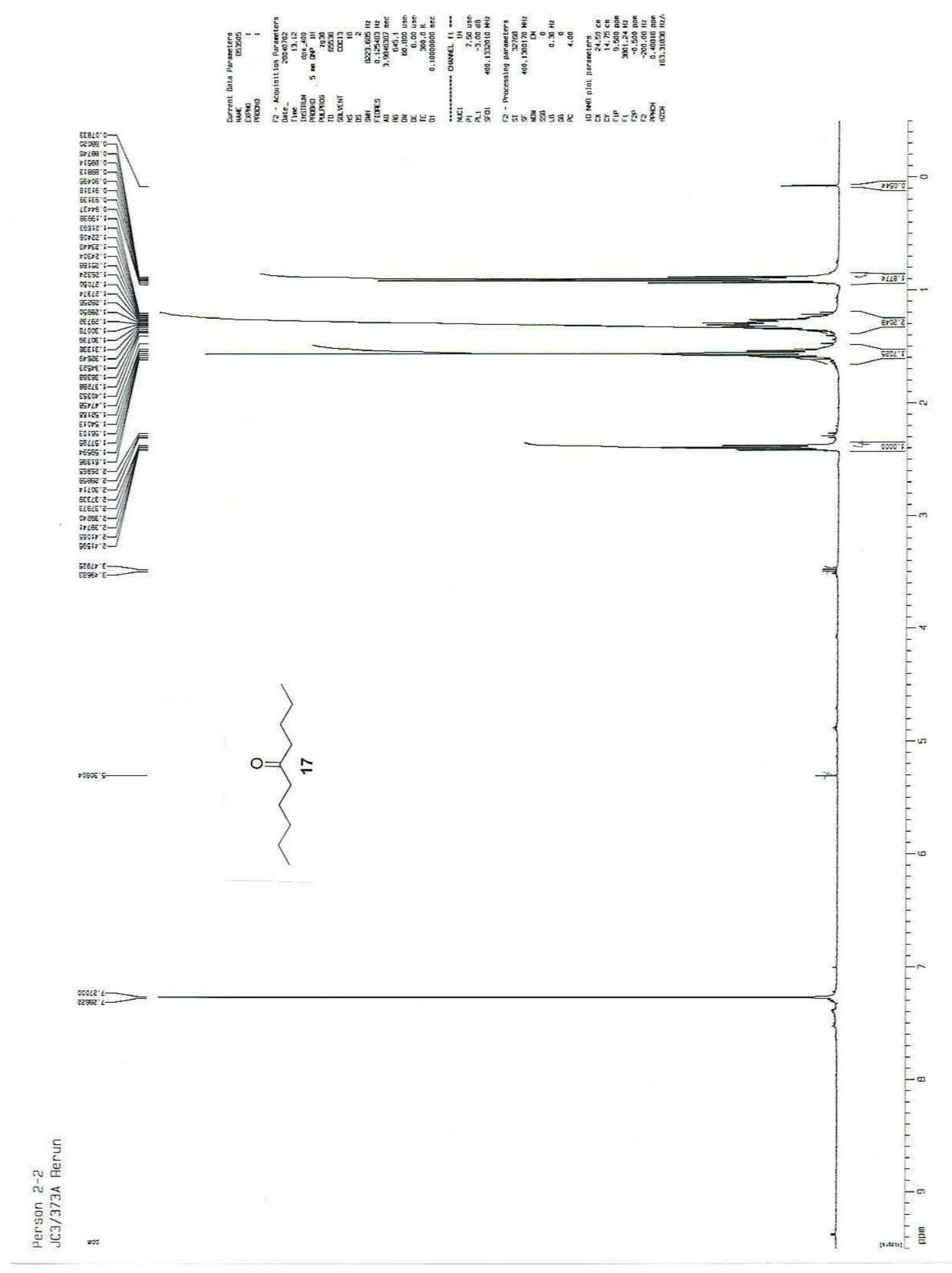




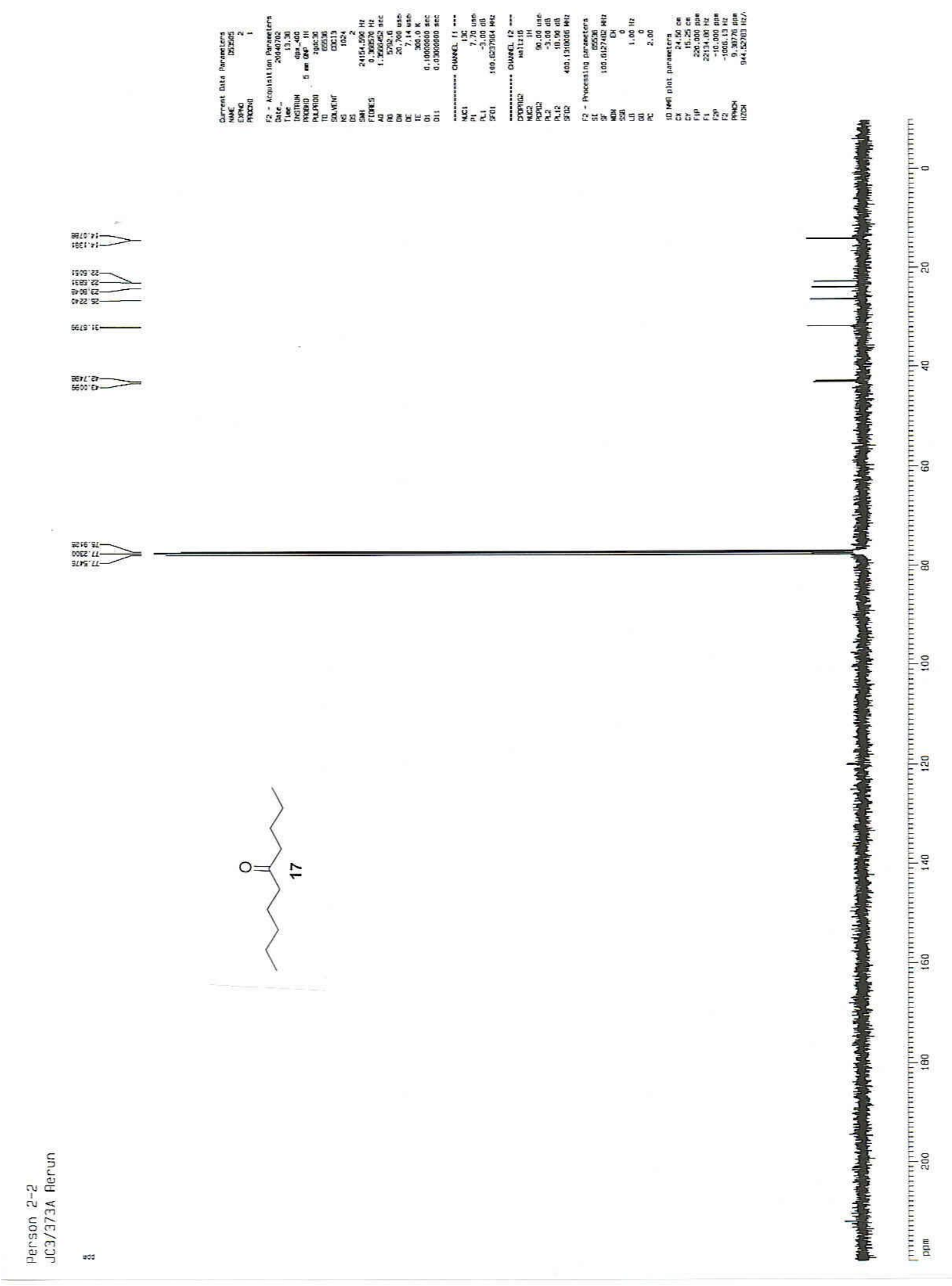




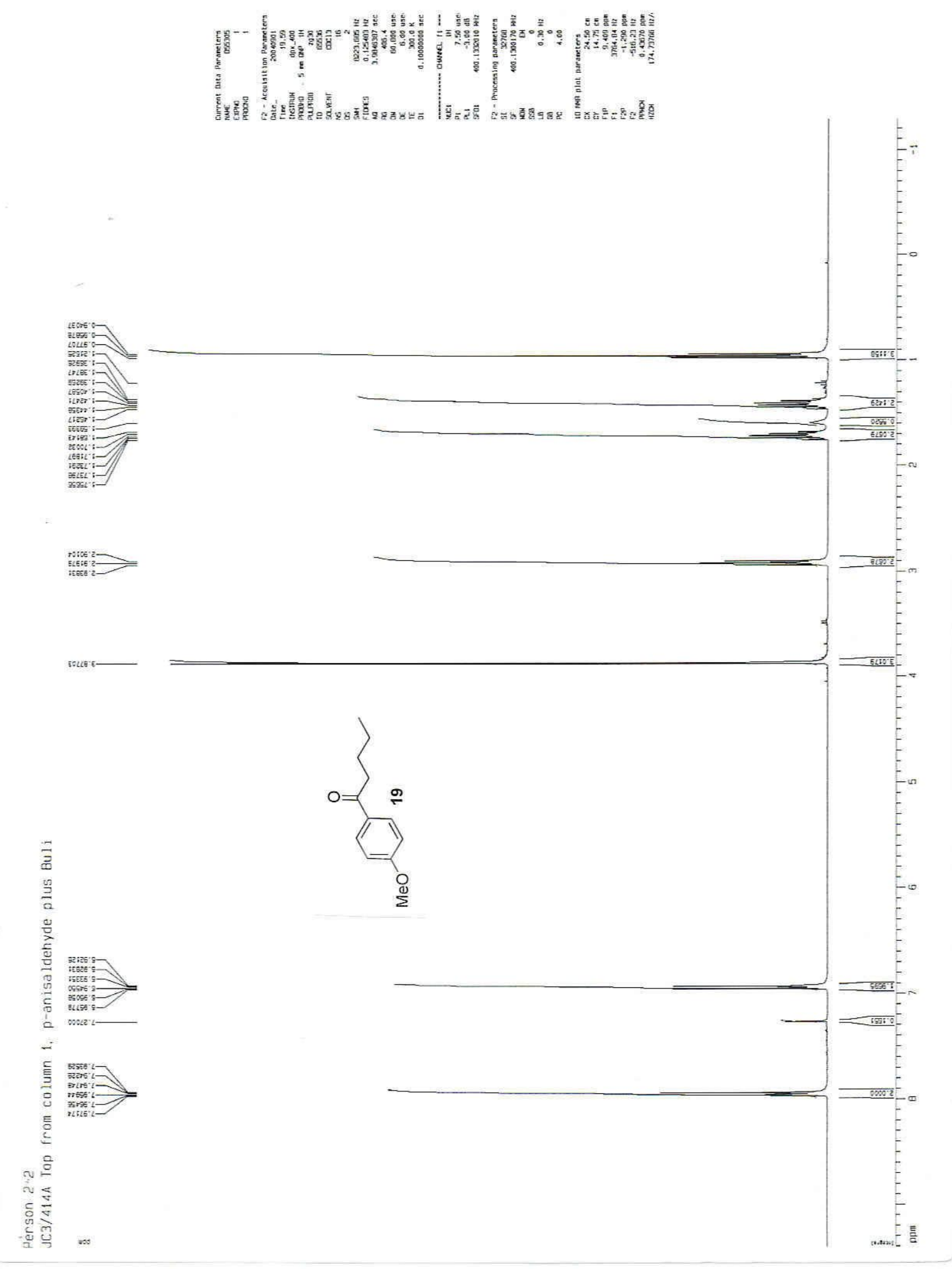




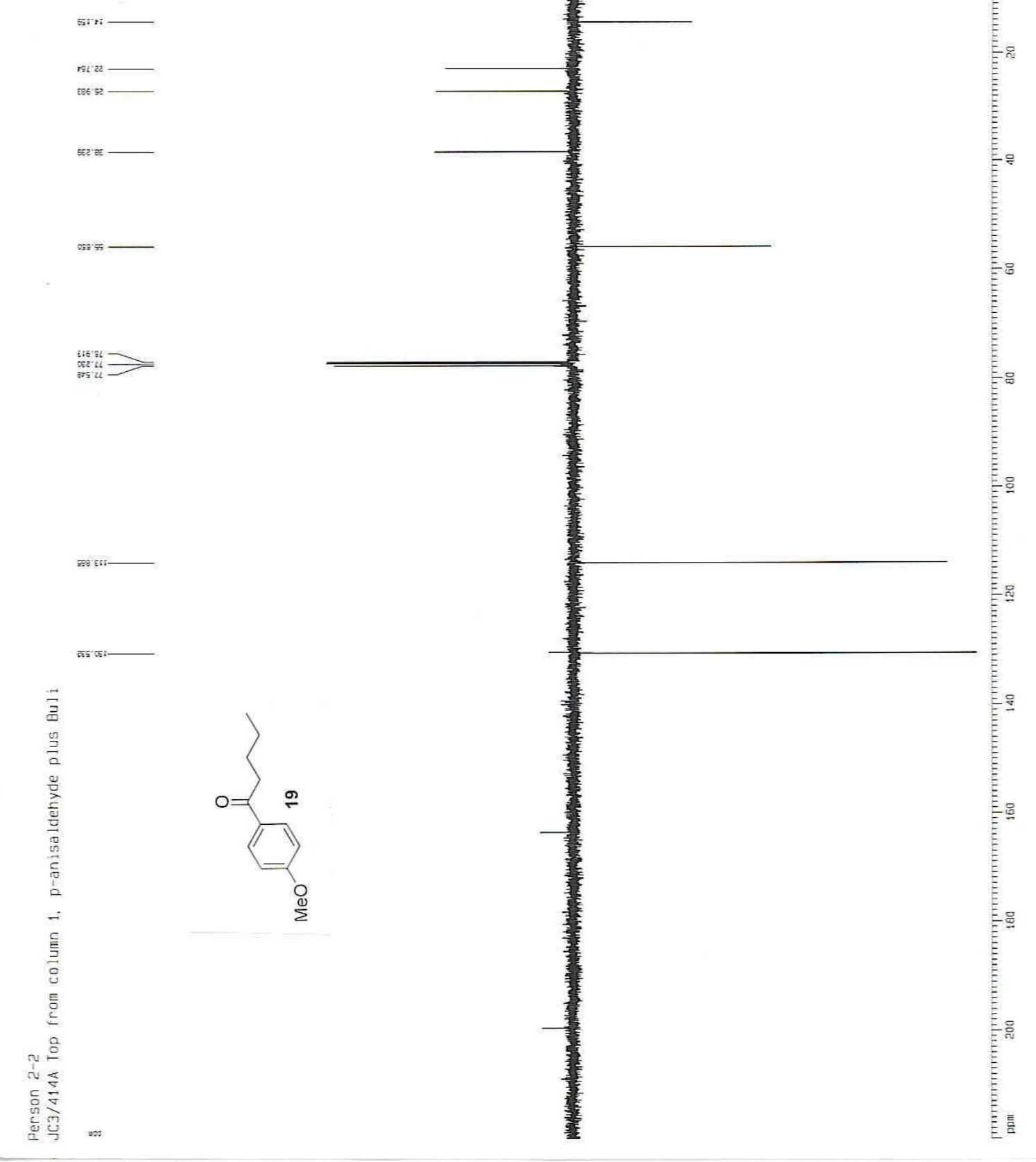




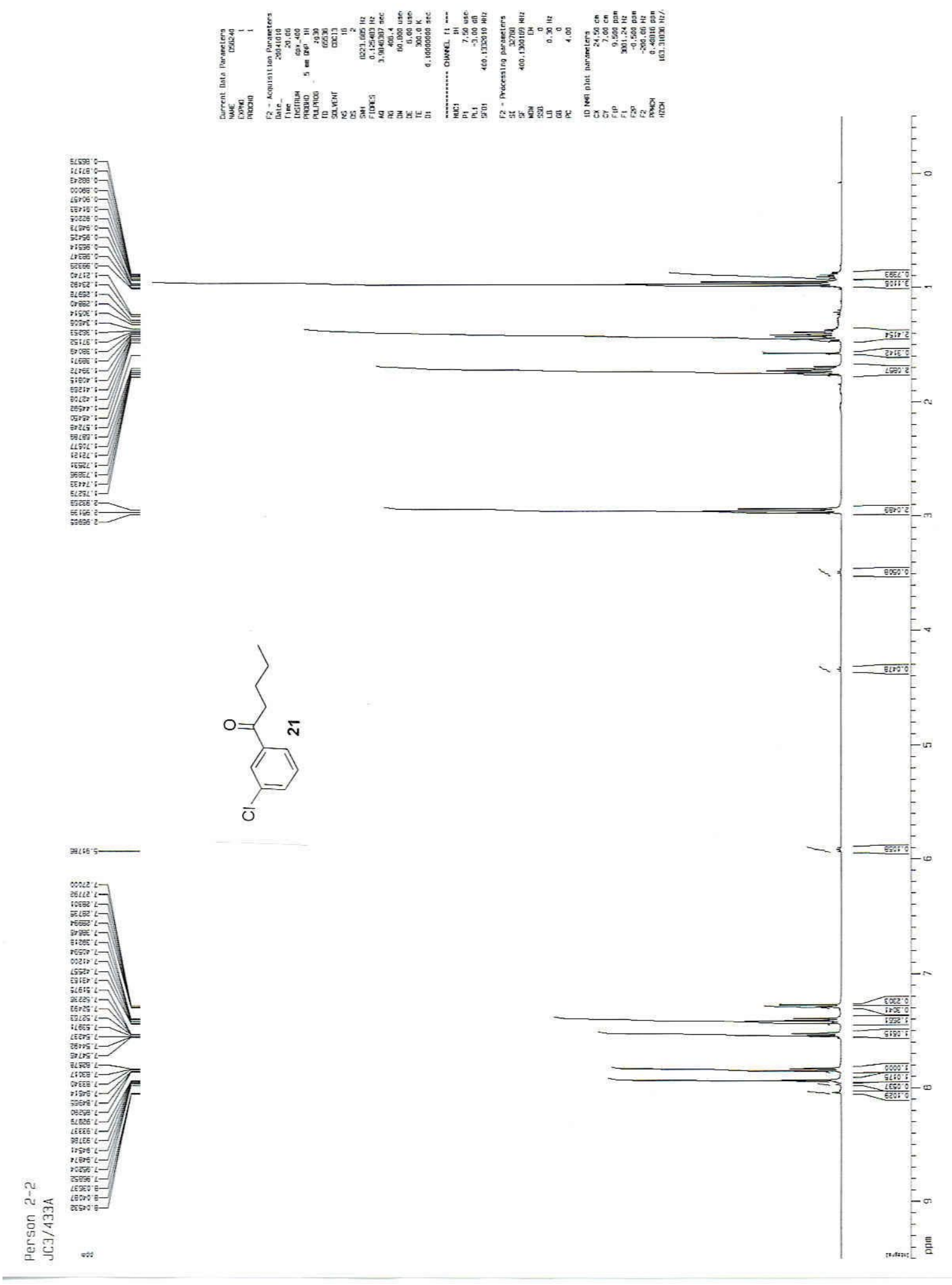



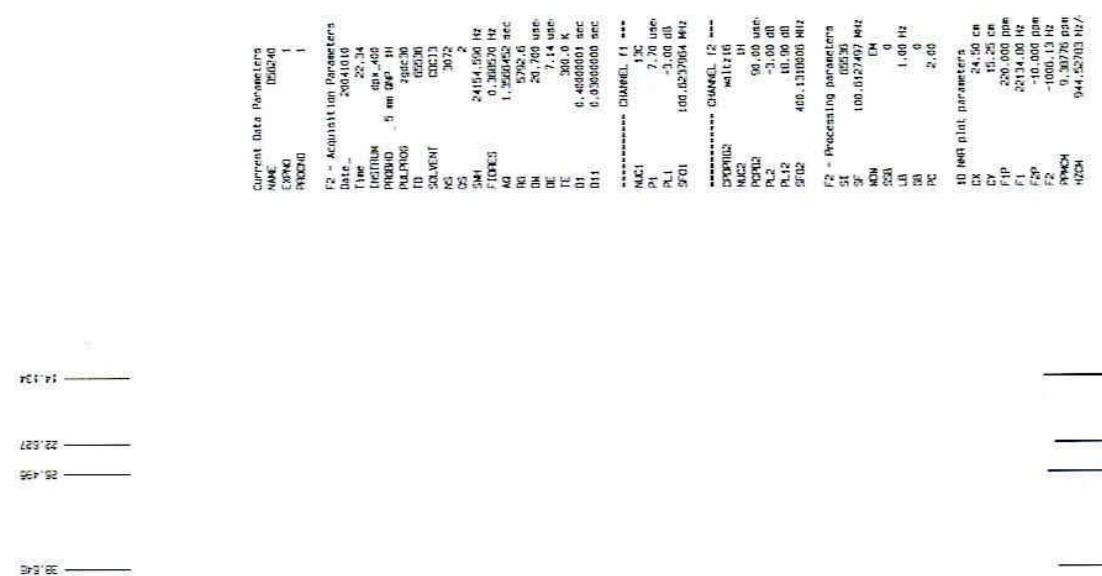

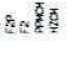
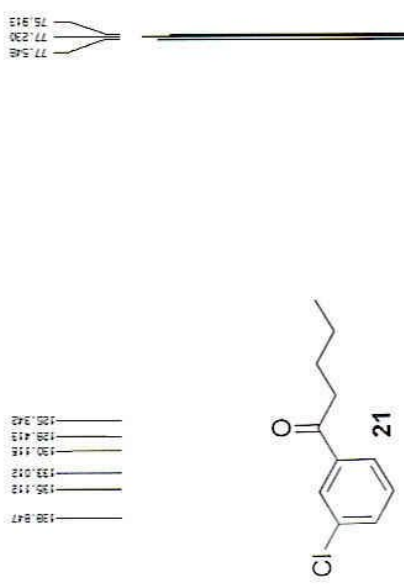

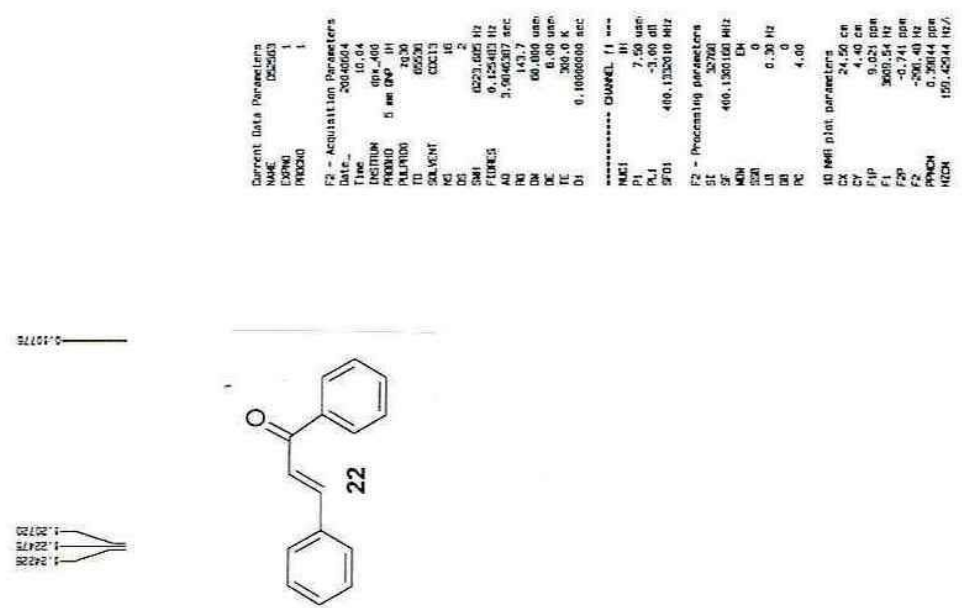

DeErE-
DoNO5:-

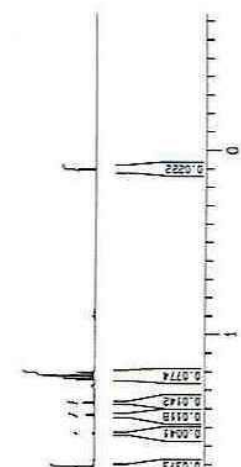

otti:

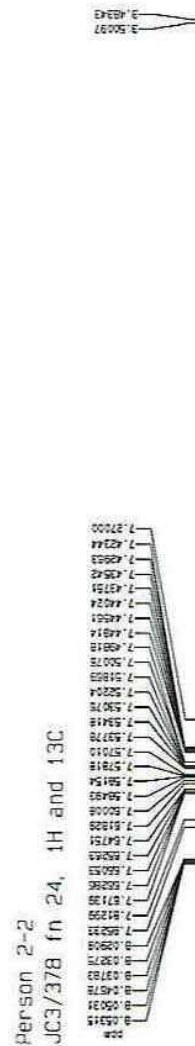




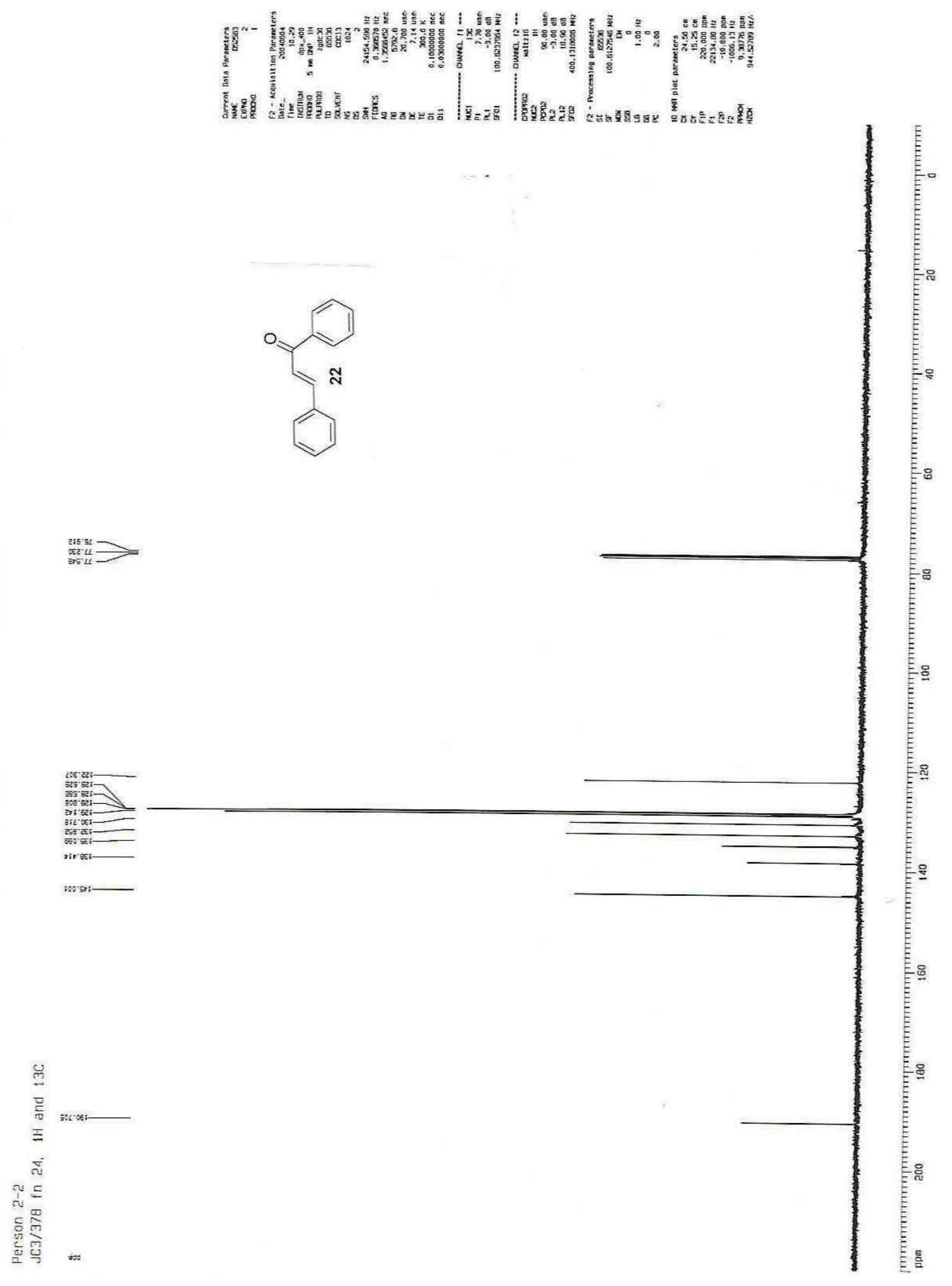




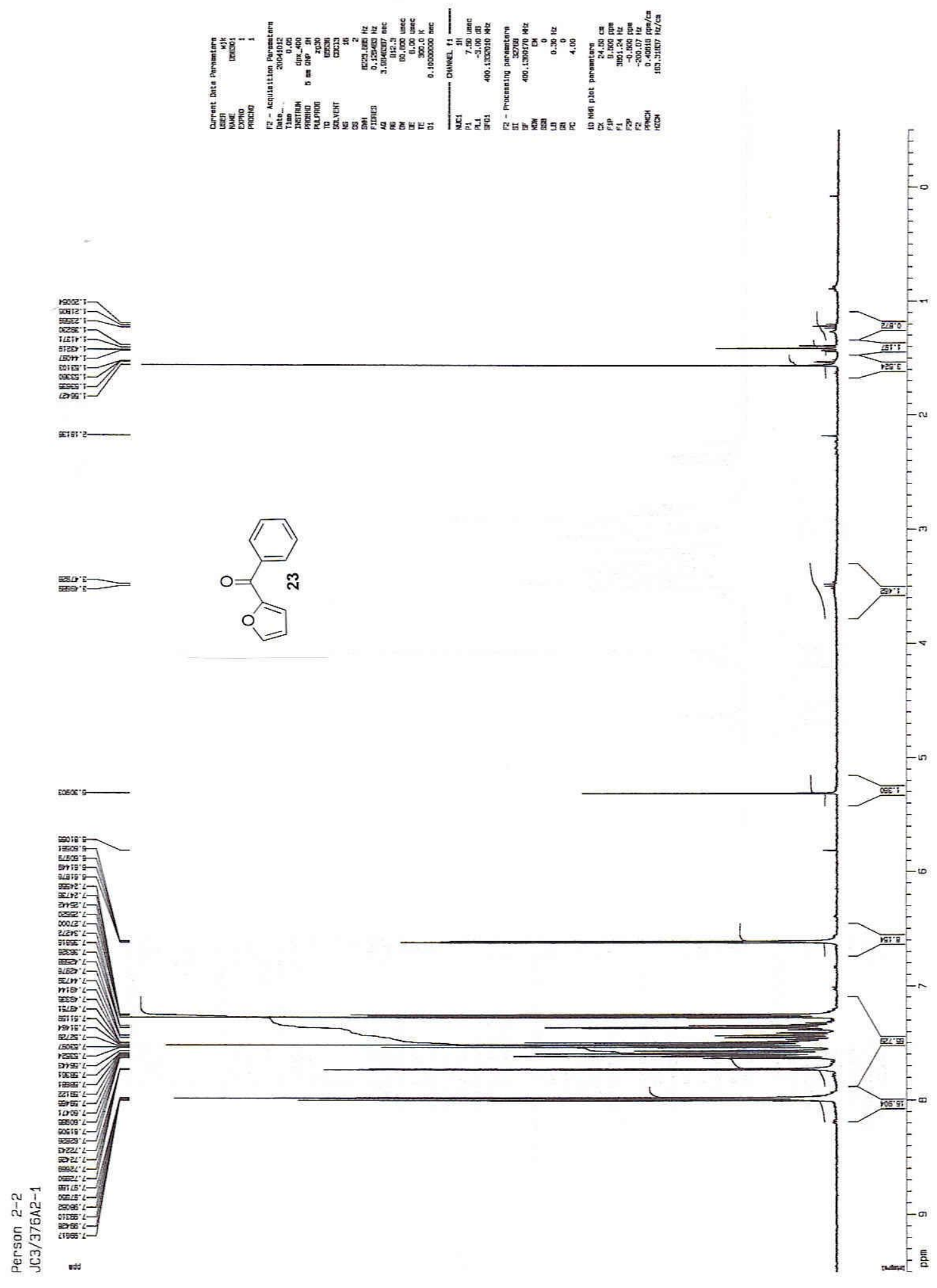




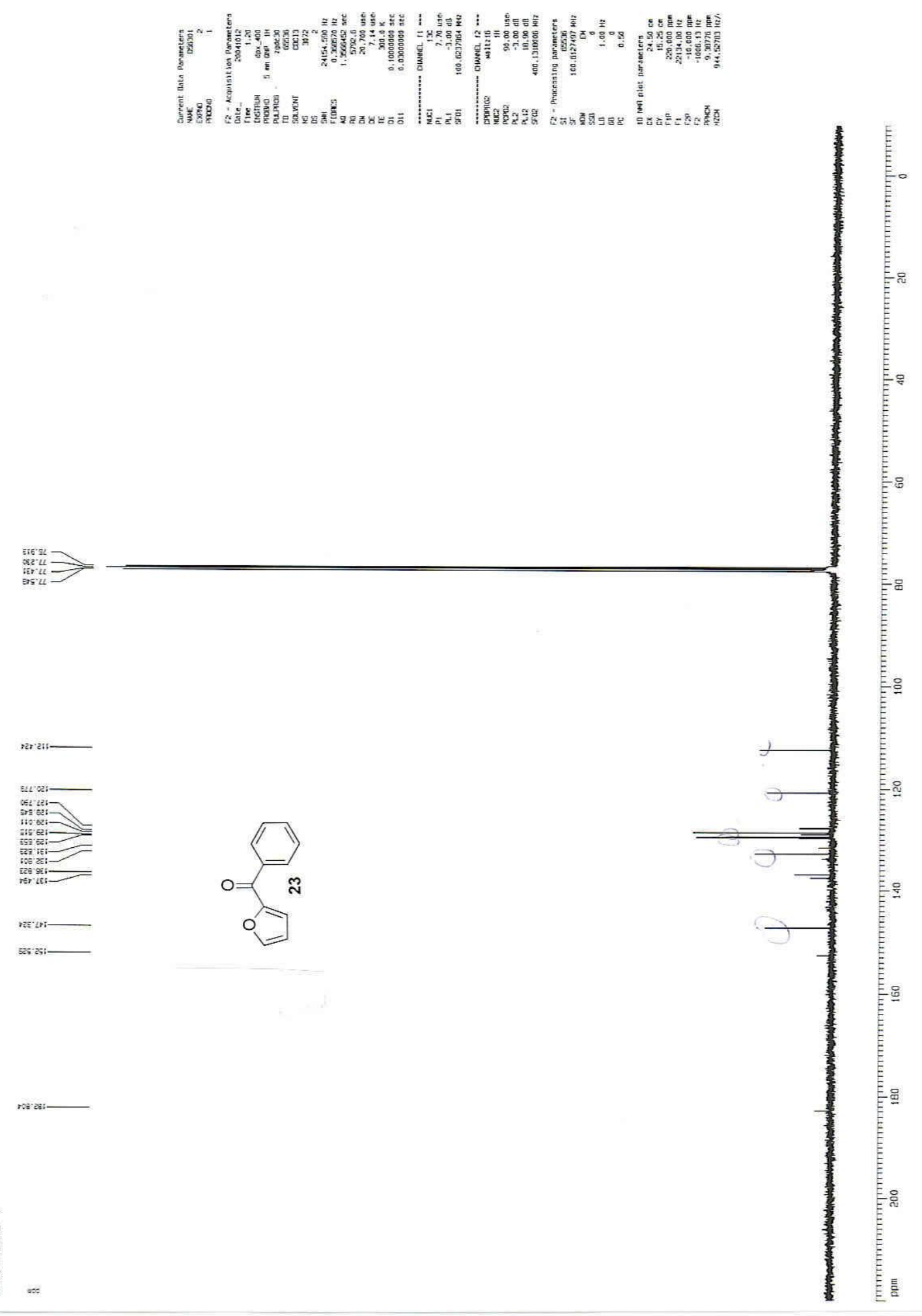



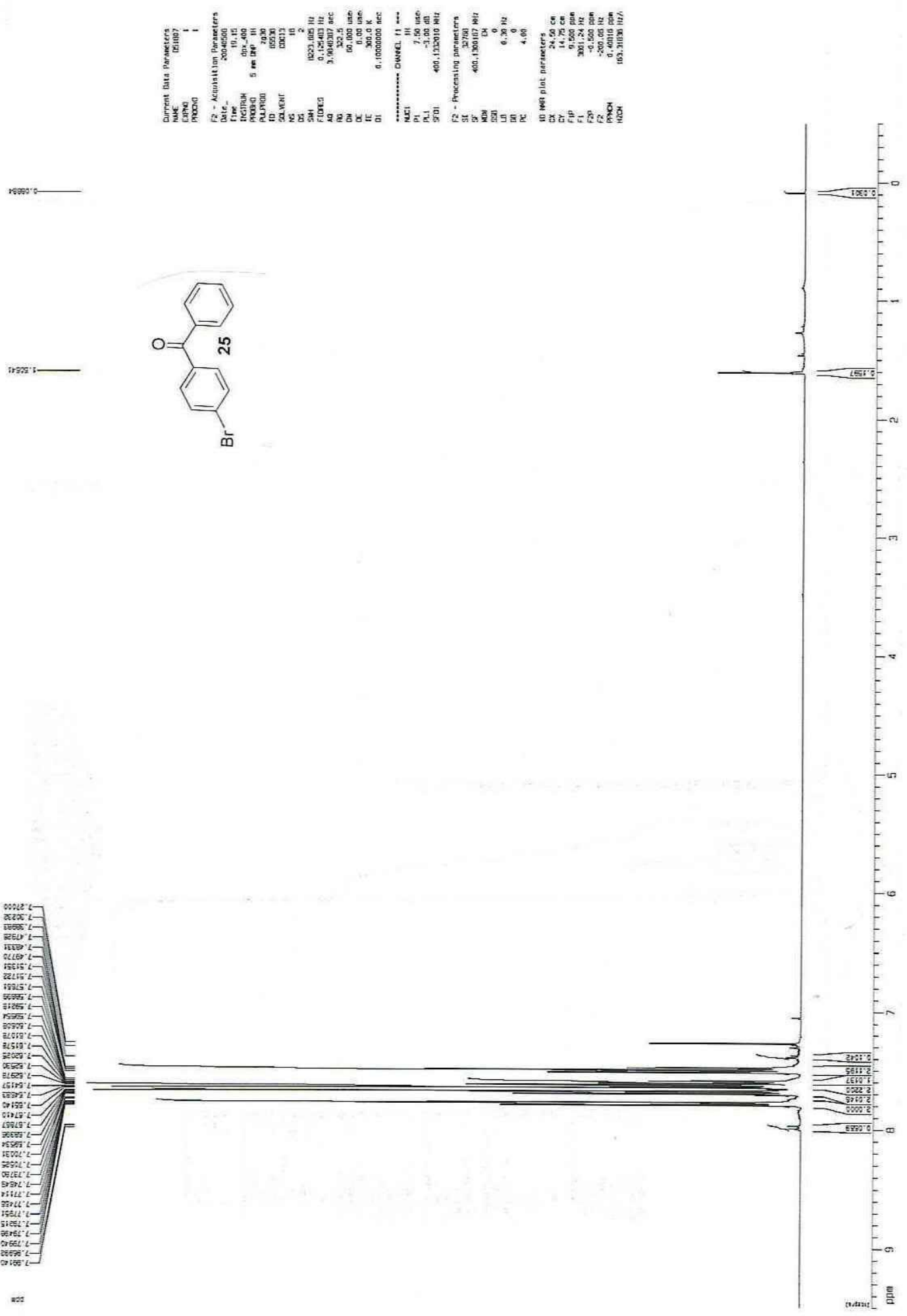


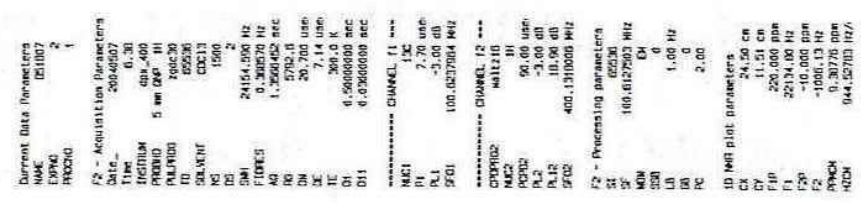

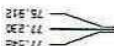

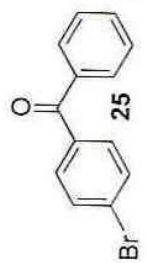

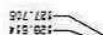

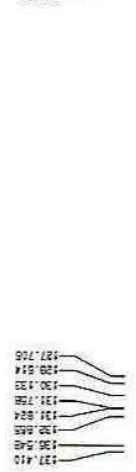

restit

argos:-

m

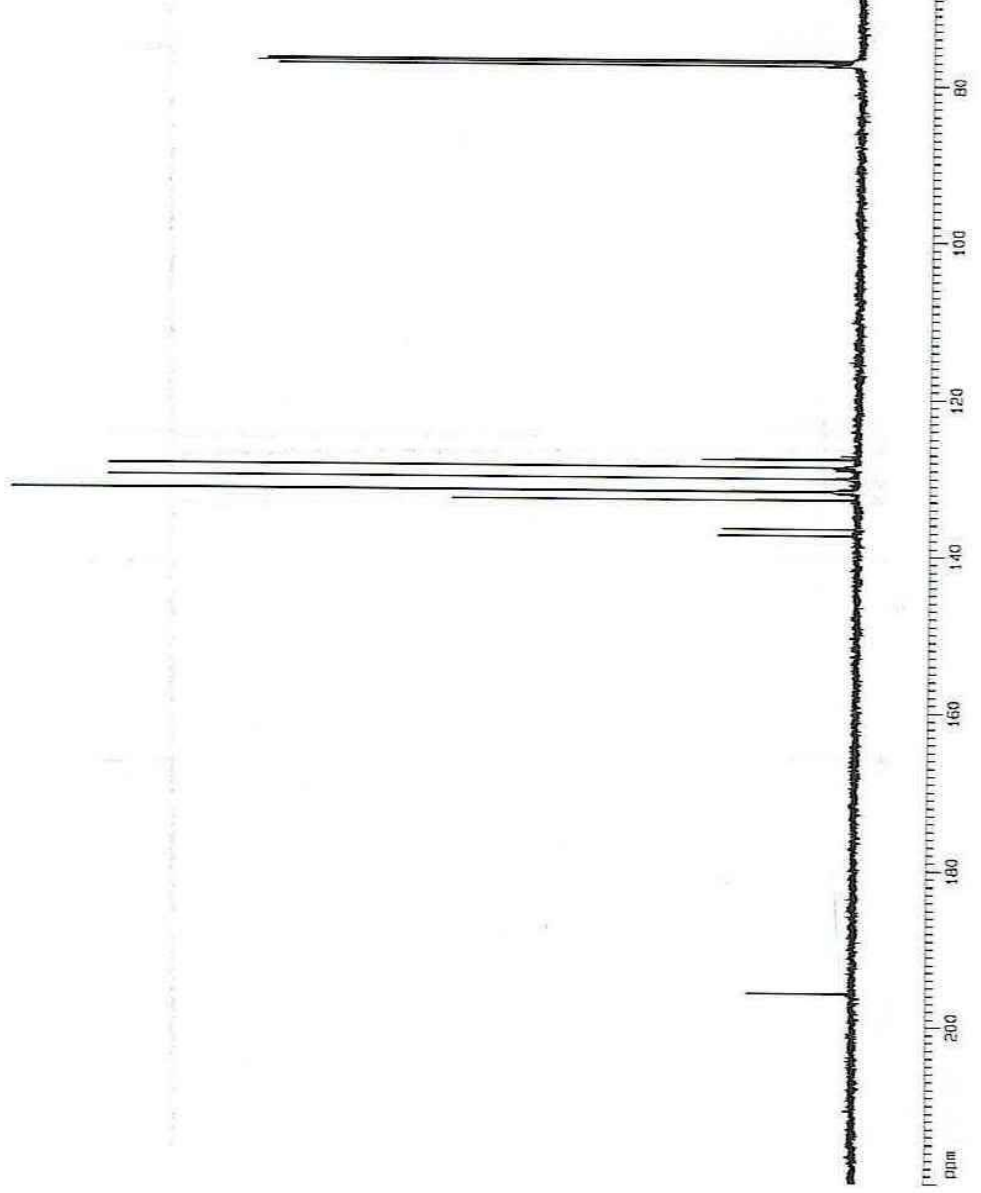

